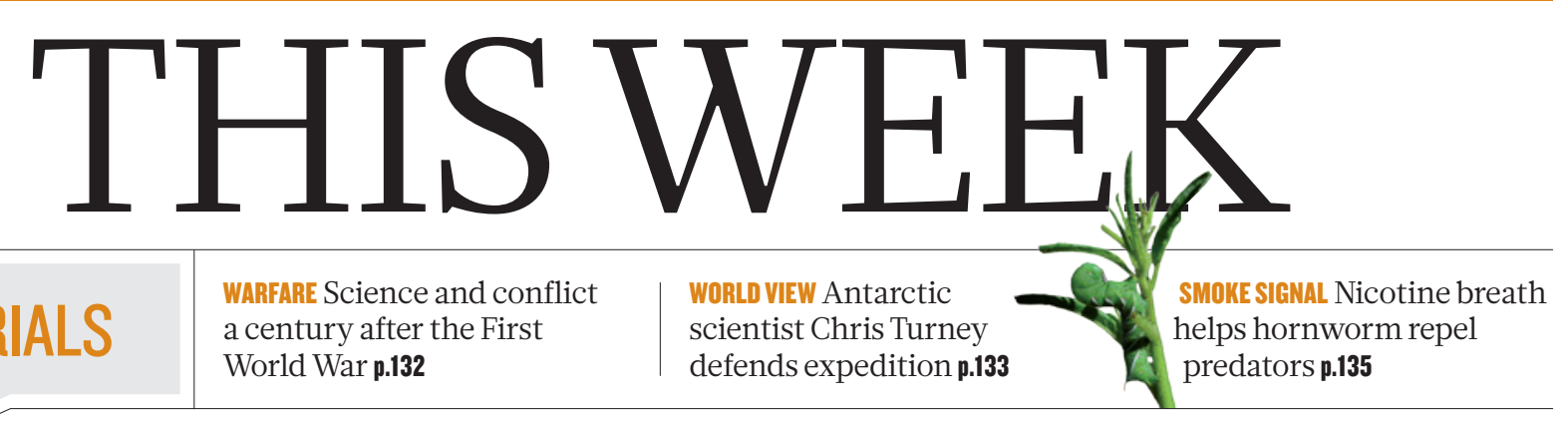

EDITORIALS
WARFARE Science and conflict World War p.132 scientist Chris Turney defends expedition $\mathbf{p} \mathbf{. 1 3 3}$ helps hornworm repel

predators $\mathbf{p} .135$

\title{
Data sharing will pay dividends
}

\author{
As public pressure builds for drug companies to make more results available from clinical trials, \\ the industry should not forget that it relies on collective goodwill to test new therapies.
}

$\mathrm{R}$ eaders of Nature who are familiar with recent controversies surrounding clinical trials and medical practice may find it bizarre that anyone could be "surprised and concerned to discover that information is routinely withheld from doctors and researchers about the methods and results of clinical trials", as stated in a UK government report last week.

After all, campaigning doctors have warned for years that pharmaceutical companies have in the past concealed data that reflected poorly on their drugs. Regulators - notably the London-based European Medicines Agency — have pushed for more information to be released into the public domain. And the drug industry itself has moved to open its private data vaults, albeit not by as much or as quickly as campaigners would like.

The 'surprise' and 'concern' at this well-chronicled behaviour of big pharma comes in a report from the UK Parliament's Committee of Public Accounts, a cross-party group with the remit to scrutinize whatever public-expenditure topic catches its eye. The report focuses on the antiviral drug Tamiflu (oseltamivir) — used to treat influenza - which the UK government and others have stockpiled at great expense owing to concerns about pandemic flu.

Independent scientists who want to investigate whether Tamiflu works have struggled to find all the information they need, in part because its manufacturer Roche, headquartered in Basel, Switzerland, held back some details of trials. The company says that it has now released all its Tamiflu data, and researchers are working their way through them, but the case has become a high-profile example of the need for greater openness in biomedical science.

The report made headlines in the United Kingdom and, according to campaigners, vindicated their position. Its call for the UK government to improve the availability of clinical-trial information is also in line with initiatives elsewhere.

For instance, the European Medicines Agency is already pushing forward plans to release the clinical-trial data that drug companies submit to it when seeking approval for their products. Legal action taken against the agency by two aggrieved companies has slowed progress. But in December, the body again stated its "firm commitment to pursuing the objective of full transparency regarding clinical trial data".

Meanwhile, the European Union is overhauling its clinical-trial legislation. Final agreement is some months away, but it seems likely that pharmaceutical firms will eventually be required to upload at least a summary of all their trials to a publicly accessible website.

The two major drug-industry associations in Europe and North America have also moved towards openness. Their joint policy on access to clinical-trial data came into force at the start of this year, adding to promises made by individual companies such as GlaxoSmithKline, Sanofi and Roche to share more data on their drugs.

Yet critics - notably the AllTrials campaign group - say that the industry is not going far enough. Their main complaints are that

transparency initiatives are not retrospective and do not require the inclusion of data from older trials, and that some in industry want to act as information gatekeepers, determining which researchers have a genuine need for their expensively assembled data sets. These campaigners deserve credit for raising the issue and for their perseverance in pushing for change.

The industry is at a crossroads. As the UK committee's report shows, concern over the behaviour of pharmaceutical firms is grow-

\section{"Recent}

history is full

of examples

of the public

turning against

businesses with essentialroles." \section{ing public health. But recent history is full} of examples of the public turning against businesses with essential roles. From banks and energy firms to the oil industry, an increasingly networked and ethically aware public is now capable of dramatic and damaging pushbacks against disliked companies.

It may be true that the worst practices of big pharma are behind it, but shades of that bad attitude linger. And past misdeeds have a habit of coming back to bite. Drug companies must remember that they need the public and its goodwill to test their medicines in the first place. They may have to release more information than they would like, but if they do, it will safeguard the trust and support of the people on whom they ultimately rely.

\section{Risk management}

Teams aimed at preventing violence on campus can offer a lifeline to those in crisis.

$\mathrm{H}$ ow safe is your workplace? It is nearly four years since biologist Amy Bishop walked into a faculty meeting with a loaded pistol and shot six of her colleagues, killing three. Acts of violence involving multiple victims are extremely rare, especially on college campuses, which tend to be safer than the areas that surround them. But highly publicized events such as Bishop's rampage and the shooting at Virginia Polytechnic Institute and State University in Blacksburg in 2007 - which had one of the highest death tolls of any attack on a college campus - have spurred rapid growth in what is known as threat assessment and management. Developed by behavioural psychologists 